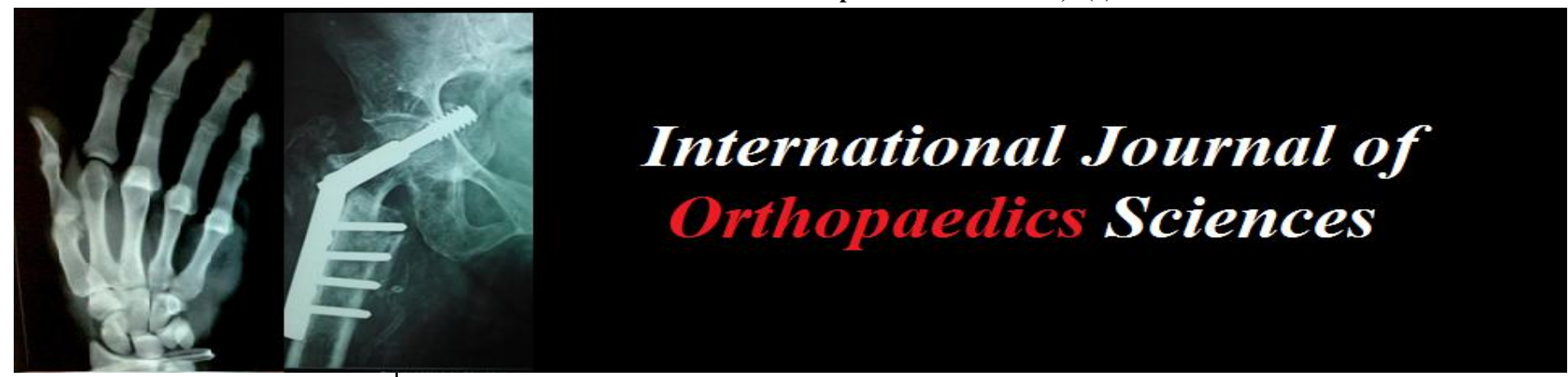

ISSN: $2395-1958$

IJOS 2017; 3(4): 406-411

(C) 2017 IJOS

www.orthopaper.com

Received: 12-05-2017

Accepted: 17-06-2017

Dr. Santhanakumaran D

Senior Resident, Department Of

Orthopedics, Government

Thiruvannamalai Medical

College, Chennai, Tamil Nadu,

India

Dr. Balachandar S

Assistant Professo, Department

Of Orthopedics, Government

Omandurar Medical College,

Chennai, Tamil Nadu, India

Dr. Kathir Azhagan S

Resident, Department of Orthopedics, Government

Stanley Medical College,

Chennai, Tamil Nadu, India

Correspondence

Dr. Balachandar S

Assistant Professo, Department

Of Orthopedics, Government

Omandurar Medical College,

Chennai, Tamil Nadu, India

\section{Outcome analysis of open fractures of the ankle joint}

\section{Dr. Santhanakumaran D, Dr. Balachandar S and Dr. Kathir Azhagan S}

DOI: https://doi.org/10.22271/ortho.2017.v3.i4f.56

\section{Abstract}

An open fracture presents with disruption of skin and underlying soft tissues results in a communication between the fracture and outside environment. In the treatment of open fractures, the objectives are to prevent infection, promote fracture healing and prevent complications with restoration of normal function. In our study we have reported an outcome analysis of open fractures of the ankle joint in 23 patients.

Keywords: Hip fracture; Bone turnover markers; CTX; PINP; Vitamin D

\section{Introduction}

Ankle fractures are the second most common lower limb fractures after the hip fractures and they represent $10 \%$ of all fractures with an incidence of around 137 per 100000 persons per year. Around $2 \%$ of ankle fractures are open fractures. Injuries around the ankle joint cause destruction of not only the bony architecture but also often the ligamentous and soft tissue components. With Fractures of the ankle, only slight variation from normal is Compatible with good joint function. Hence analyzing their functional and radiological outcome is mandatory.

\section{Aim of the study}

To study the functional and radiological outcome of open ankle fractures treated by various modalities.

\section{Materials and Methods}

This is a prospective and retrospective study of open ankle fractures conducted at Institute Of Orthopedics And Traumatology, Rgggh, Madras Medical College, Chennai-3 between june 2015 to june 2016. Institutional ethical committee clearance obtained for the above study and written informed consent obtained from all patients who were selected according to the following inclusion and exclusion criteria.

\section{Inclusion Criteria}

The following open ankle fractures were included in the study

GR I, GRII, GRIIIA \& GRIIIB (Gustillo - Anderson) open fractures of

1) Medial malleoli

2) Lateral malleoli

3) Bi malleolar

4) Tri malleolar

5) Ankle dislocations

\section{Exclusion Criteria}

The following fractures were excluded

1) GR III C open fractures

2) Associated crush injuries of the foot \& Mangled extremities

3) Open distal tibial pilon injuries

4) Talus fractures - which were highly comminuted 


\section{Methodolgy}

All the patients who were admitted in the trauma ward are resuscitated as per ATLS protocol. Patients were stabilized and revived from hemodynamic shock if present with administration of iv fluids and blood if needed.

Complete examination of the injured extremity done following resuscitation and assessment of open wound grading and nature of contamination noted. Immediately a preliminary wound wash given with normal saline in the emergency room itself and sterile dressing applied. All patients were then administered with a dose of cephalosporin (inj. Cefotaxime $1 \mathrm{~g}$ iv) and if the contamination and the grade of open wound is more, aminoglycoside (inj. amikacin) and inj. metronidazole were added. Tetanus prophylaxis given and if the wound is highly contaminated inj. Anti tetanus immunoglobulins administerd immediately.

After the initial resuscitation and evaluation, a complete trauma evaluation done with a routine trauma series radiography (x rays of cervical spine, chest, pelvis with both hips, abdomen, lumbar \& dorsal spine taken) in addition to the $\mathrm{x}$ ray of the involved extremity. After examining the $\mathrm{x}$ rays of the ankle (AP, Lateral and mortice views) if needed, a CT scan of the ankle is taken.

Patients then completely evaluated with all routine blood investigations and prepared for emergency wound debridement and skeletal stabilization.

We did Open reduction and internal fixation with cancellous screws and 1/3 tubular plate for all Gr I open fractures. Gr II fractures were managed with ORIF or external fixation with internal fixation depending upon the wound status.

Gr III A \& GR III B fractures were managed with minimal internal fixation and external fixation or external fixation alone check radiographs were taken.

Patients were managed in ward with routine inspection of the wound status and antibiotics continued for prescribed time. If a wound shows any signs of infection a culture is taken and antibiotics changed according to the sensitivity reports. Depending upon the wound status, a spilt thickness skin graft (SSG) or flap cover done if needed.

The discharged patients were followed up at 3 weeks, 6 weeks and 2 months. During the follow up the wound status and fracture healing status assessed and external fixators removed if the wound has healed and patients were put on below knee casts for 3 to 4 weeks.

Patients functional outcome analysed with Olerud and molander ankle score (OMS), Baird and Jackson ankle score and AOFAS (American orthopedic foot and ankle score) scores.

\section{Results and Observation}

The observations and results from our study as follows

- The common age group who presents with open ankle fractures belong to middle age group followed by older age

- Open ankle fractures predominant in male (87\%) compared to female (13\%)

- The most common cause in our study is road traffic accidents (69\%), followed by self fall (13\%) and fall from height $(13 \%)$

- Majority of the patients presents as Gr III A open fractures ( gustilo - Anderson ) $43.5 \%$ followed by GR III B open fractures ( 30.4\%) and bi malleolar fractures are common $(60.9 \%)$

- Based on the observations of the Lauge - Hansen and AO/OTA classifications, supination external rotation type
4 (SER 4) and type 44a2 (AO) are more prevalent.

- $\quad 34 \%$ of the patients required the plastic procedures in the form of SSG \& flap cover and $39 \%$ wounds healed with secondary intention.

- Outcome analysis based on olerud molander score $61 \%$ of patients show good results and $39 \%$ patients show fair results.

- $\quad$ Based on baird - Jackson scoring system $69.67 \%$ patients show poor results as this criteria includes radiological criteria in to the scoring. $13 \%$ of patients show good results and $17 \%$ show fair results.

- AOFAS (American orthopedic foot and ankle society score) - out come score shows $73 \%$ patients with good results and $26 \%$ with poor results.

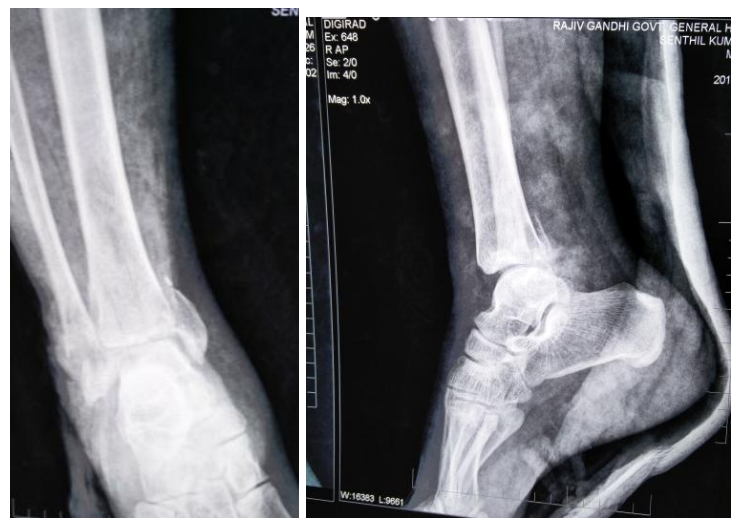

Case illustrations - case i pre op

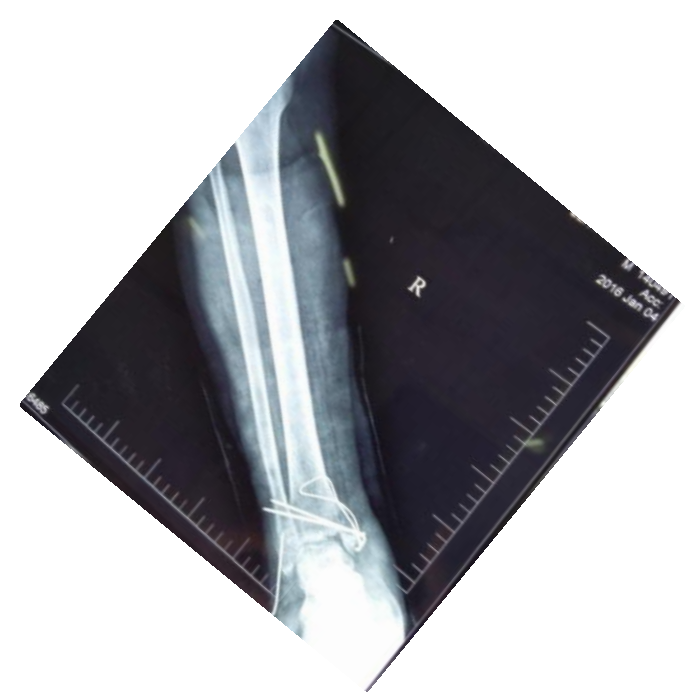

Immediate post op

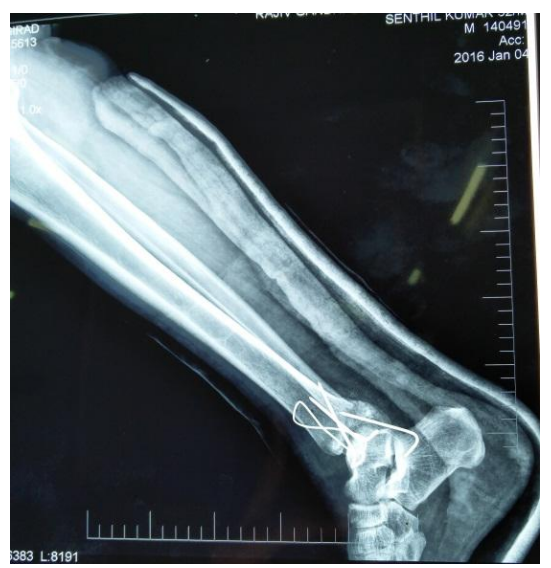

6 weeks follow up 

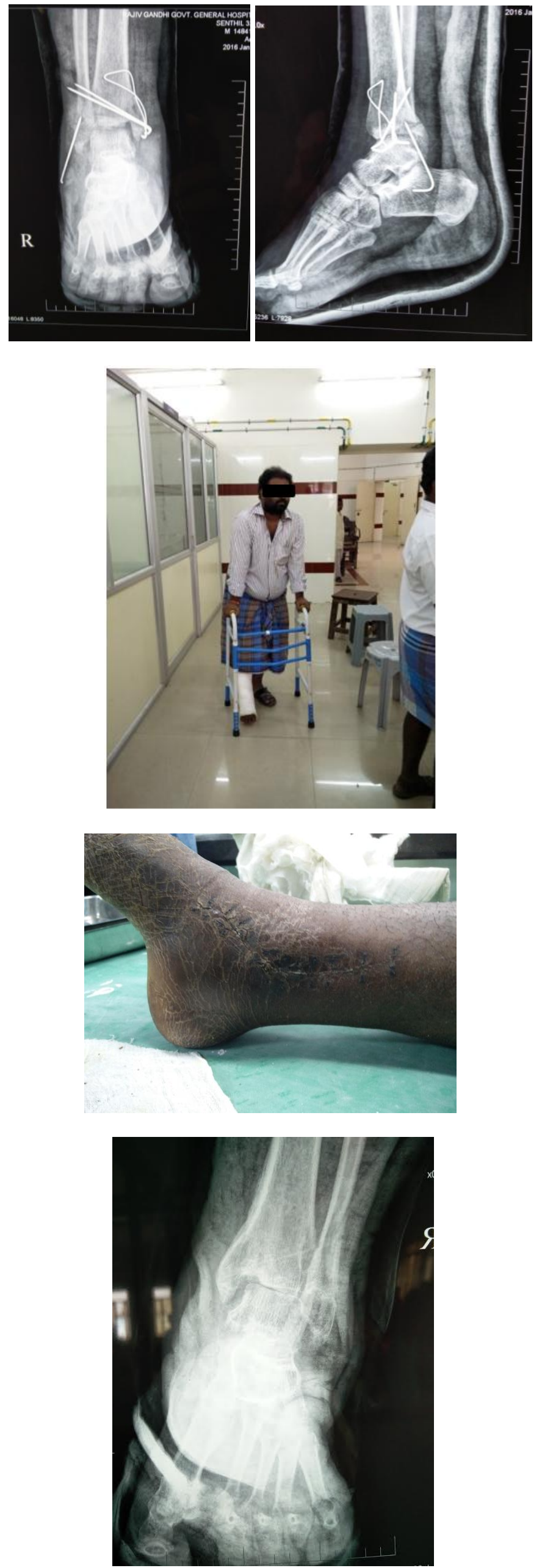

9 months after implant exit
Case II

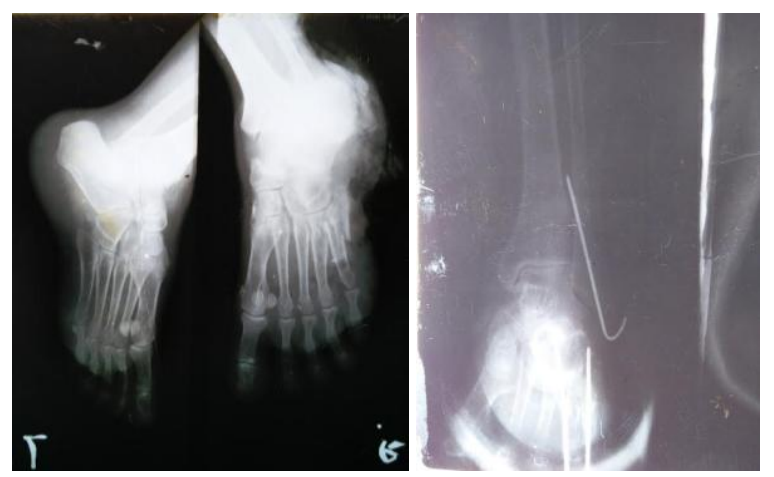

Pre op

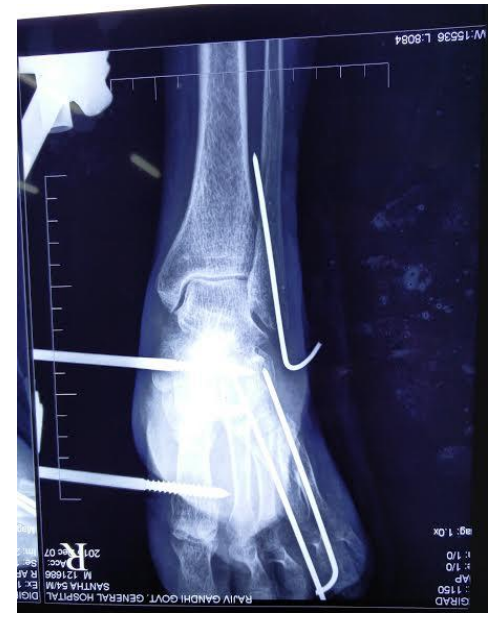

Immediate post op

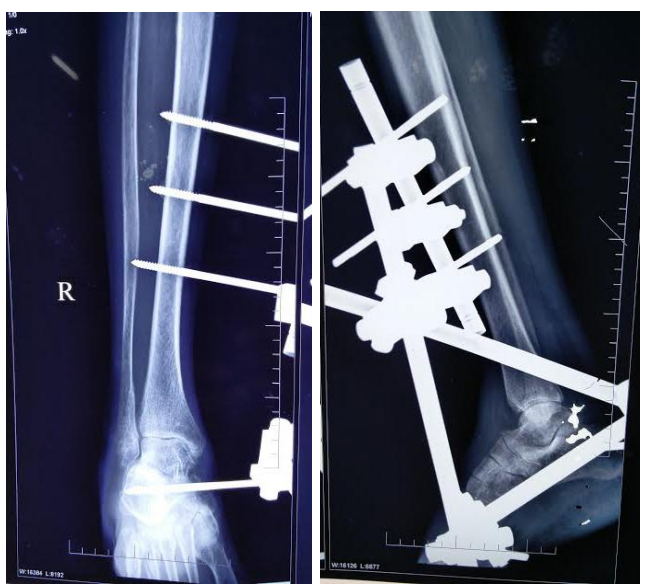

6 Weeks Follow Up

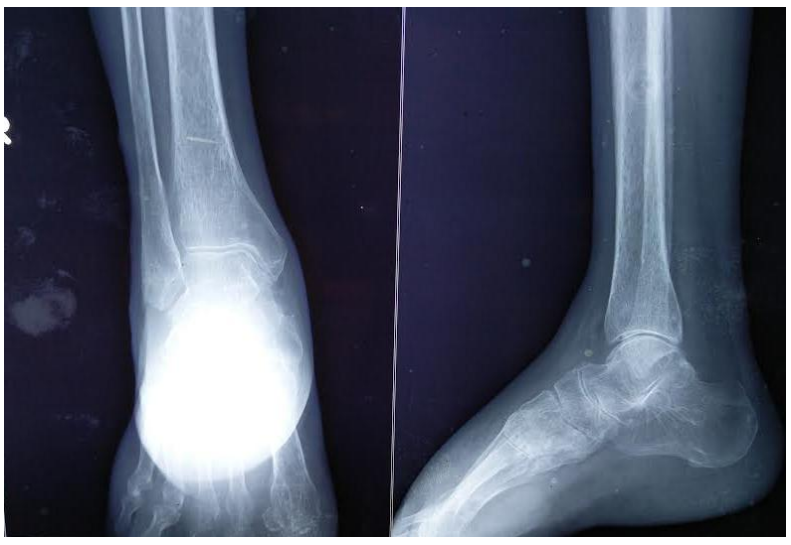

After Implant Exit 
10 Months Follow Up
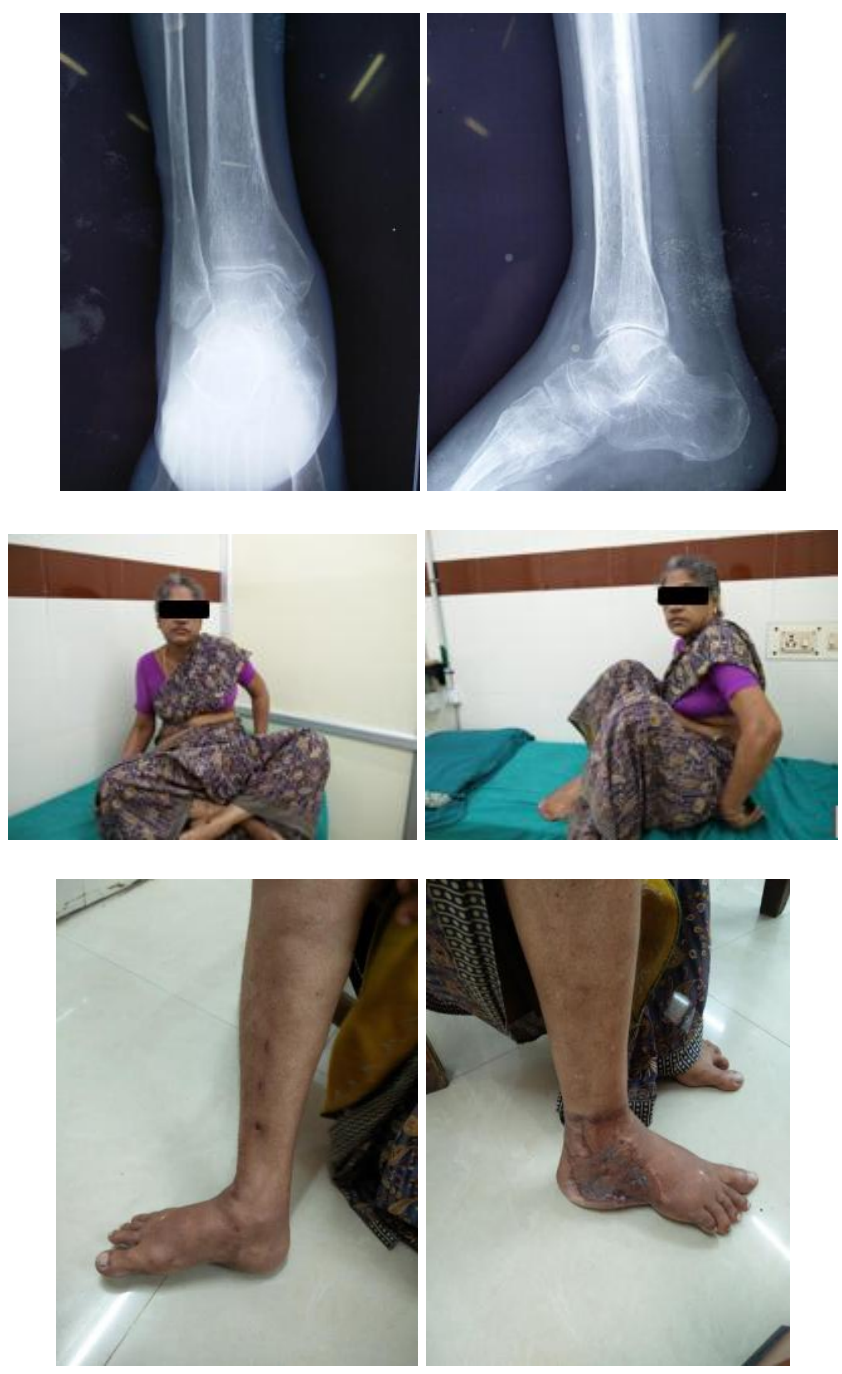

\section{Discussion}

In our study of 23 patients with open fractures of the ankle, the mean age is 41.74 years. In a study of epidemiology of ankle fractures by Charles M Court-Brown et al the mean age group was 45 years, In the 3-year study period, 1,500 ankle fractures were treated in the Edinburgh Orthopaedic Trauma Unit.

In our study male patients are predominantly involved (87\%) and the most common cause being road traffic accidents $(69.6 \%)$, followed by self fall (13\%) and fall from height (13\%).

The epidemiology appears to be varying with time: Between 1950 and 1980 an increase in incidence amongst younger males and elderly females was seen - BENGNER et al (Acta orthop scandinavia).

However more recently the incidence amongst younger males has appeared to remain static whilst the increase in elderly women has continued- THUR CK et al (epidemiology of ankle fractures - Acta orthop 2012) ${ }^{[39]}$ \& KOVAL KJ et al (J orthop trauma 2005) ${ }^{[40]}$

The mechanism of injury has also changed with a reduction in fractures occurring because of severe trauma between 1950 and 1980 and a concomitant increase in the proportion of fractures caused by sporting activity in males.

The already high incidence of ankle fractures is increasing sharply in line with the ageing demographic of most Western populations. Kannus et al. reported an increase of $319 \%$ in the overall annual number of low-energy ankle fractures in elderly patients admitted to hospital over the three decades between 1970 and 2000. From this data they predicted that the number of low-energy ankle fractures could be expected to triple by 2030. They forecast a higher rate of increase in females.

The epidemiology of the specific fracture patterns does however vary. Patients with an AO/OTA type $\mathrm{C}$ fracture more commonly sustain their injury because of a fall from a height or a motor vehicle accident than patients with AO/OTA type A or B fractures in which the most common cause is a simple fall - COURT BROWN CM et al.

In our study RTA is the predominant mode of injury with AO fracture types $44 \mathrm{a} 2$ and $44 \mathrm{~b} 2$ more prevalent followed by $44 \mathrm{c} 1$.

With regard to the grade of open fractures, we get more number of GR III A open fractures (43.5\%) and GRIII B fractures $(30.4 \%)$ than GR $1(8.7 \%)$ and GRII (17.4\%) fractures, since our institute is the tertiary care referral centre. This is also attributed the increase in the number of high vlocity road traffic accidents. UMRAZ KHAN et al (Management of Severe Open Ankle Injuries) - "If the viability cannot be guaranteed and there are other impediments to wound healing (e.g., diabetes, high alcohol intake, intravenous drug abuse), one should delay internal fixation until the skin has declared itself to be viable."

All the fractures were debrided and skeletal stabilisation done within 24 hours, most common method of fixation in our study $(47.8 \%)$, ankle spanning external fixation with $\mathrm{k}$ wires (minimal internal fixation). The wound healing is by secondary intention $39.1 \%$ of cases, and a plastic procedure in the form of SSG or Flap cover needed in $34.3 \%$ of cases. Internal fixation was done in $21.7 \%$ cases ( 5 cases) - GR I - 2 cases and GR III -3 cases.

The functional outcome shows $69.1 \%$ good results and 39.1 $\%$ fair results (OMAS score) and 13\% good, $17.4 \%$ fair, $69.6 \%$ poor (baird jackson score) and $73.1 \%$ good and $26.1 \%$ poor results (AOFAS score), in which baird jackson score includes radiological parameters also in scoring.

The incidence of PTOA has been reported as high as $70 \%$; with rotational AF being the most common cause HORISBERGER M et al (J Orthop Trauma 2009; 23:60.7.) It occurs following a failure of restoration of normal anatomy due to $\mathrm{mal} /$ nonunion and is the most common indication for ankle arthrodesis. When there is a significant displacement, anatomical reduction is more likely to be achieved through surgical means thus reducing long term risk of developing PTOA. This is especially true in cases of the lateral talar displacementwhere $1 \mathrm{~mm}$ displacement has been shown to reduce the tibio. talar contact area by an average of $42 \%$ resulting in peak loads - RAMSEY PL et al (J Bone Joint Surg Am 1976;58:356.7.) ${ }^{[22-24]}$.

It has been shown the latency time between injury and developing end.stage ankle OA is 20.9 years. Given the high incidence of AF in young patients, ankle arthrodesis in middle age patients is a very real consequence of PTOA. A patient journey to arthrodesis involves chronic pain leading to functional impairment, both of which significantly contribute to morbidity.

In our study arthritic changes observed in $40 \%$ of patients. So far we have not done ankle arthrodesis in our patients.

\section{Conclusion}

The complexity of the open ankle fractures warrents treatment by orthopaedic surgeons who are experienced in this fractures. 
Emergency wound debridement, adequate wound management, rigid skeletal stabilisation improves the outcome significantly.

Open reduction and internal fixation in GR I and GRII open ankle fractures reults in excellent patient outcome.

GR III open fractures managed with external fixation and minimal internal fixation provides better results compared with external fixation alone emphasise on rigid internal fixation in the management of these fractures.

\section{References}

1. Court-Brown CM, Caesar B. Epidemiology of adult fractures: A review. Injury. 2006; 37(8):691-697.

2. Court-Brown CM, McBirnie J. Adult ankle fractures-an increasing problem? Acta Orthop. 1998; 69:43-47.

3. Jensen SL, Andresen BK, Mencke S, et al. Epidemiology of ankle fractures. A prospective population-based study of 212 cases in Aalborg, Denmark. Acta Orthop Scand. 1998; 69(1):48-50.

4. Olerud S, Karlstrom G, Danckwardt-Lilliestrom G. Treatment of open fractures of the tibia and ankle. Clin Orthop Relat Res. 1978; (136):212-224.

5. Ngcelwane MV. Management of open fractures of the ankle joint, Injury. 1990; 21:93.

6. Wiss DA, Gilbert P, Merritt PO, et al: Immediate internal fixation of open ankle fractures, J Orthop Trauma. 1988; 2:265.

7. Franklin JL, Johnson KD, Hansen ST Jr. Immediate internal fixation of open ankle fractures. Report of thirtyeight cases treated with a standard protocol. J Bone Joint Surg Am. 1984; 66(9):1349-1356.

8. Bray TJ, Endicott M, Capra SE. Treatment of open ankle fractures. Immediate internal Wxation versus closed immobilization and delayed Wxation. Clin Orthop Relat Res. 1989; (240):47-52.

9. Sanders R, Pappas J, Mast J, Helfet D. The salvage of open grade IIIB ankle and talus fractures. J Orthop Trauma. 1992; 6(2):201-208.

10. Johnson EE, Davlin LB. Open ankle fractures. The indications for immediate open reduction and internal Wxation. Clin Orthop Relat Res. 1993; (292):118-127.

11. White CB, Turner NS, Lee GC, Haidukewych GJ. Open ankle fractures in patients with diabetes mellitus. Clin Orthop Relat Res. 2003; (414):37.

12. Joshi D, Singh D, Ansari J, Lal Y. Immediate open reduction and internal fixation in open ankle fractures. $\mathbf{J}$ Am Podiatr Med Assoc. 2006; 96(2):120-124.

13. Lee YS, Chen SW. Lateral Wxation of open AO type-B2 ankle fractures: the Knowles pin versus plate. Int Orthop. 2009; 33(4):1135-1139.

14. Caroline C, C Hulsker. Evidence-based treatment of open ankle fractures Arch Orthop Trauma Surg, 2011; 131:1545-1553. DOI 10.1007/s00402-011-1349-7 123

15. Lambert KL. The weight-bearing function of the fibula. A strain gauge study. J Bone Joint Surg Am. 1971; 53(3):507-513.

16. Takebe K, Nakagawa A, Minami H, et al. Role of the fibula in weight-bearing. Clin Orthop Relat Res. 1984; 184:289-292.

17. Gardner MJ, Brodsky A, Briggs SM, et al. Fixation of posterior malleolar fractures provides greater syndesmotic stability. Clin Orthop Relat Res. 2006; 447:165-171.

18. Miller AN, Carroll EA, Parker RJ, et al. Posterior Malleolar Stabilization of Syndesmotic Injuries is
Equivalent to Screw Fixation. Clin Orthop Relat Res. 2010; 468(4):1129-1135.

19. Michelson JD, Hamel AJ, Buczek FL, et al. Kinematic behavior of the ankle following malleolar fracture repair in a high-fidelity cadaver model. J Bone Joint Surg Am. 2002; 84-A(11):2029-2038.

20. McCullough CJ, Burge PD. Rotatory stability of the loadbearing ankle. An experimentalstudy. J Bone Joint Surg Br. 1980; 62-B(4):460-464.

21. Stiehl JB, Skrade DA, Needleman RL, et al. Effect of axial load and ankle position on ankle stability. J Orthop Trauma. 1993; 7(1):72-77.

22. . Ramsey PL, Hamilton W. Changes in tibiotalar area of contact caused by lateral talar shift. J Bone Joint Surg Am. 1976; 58(3):356-357.

23. Huene DB, Bunnell WP. Operative anatomy of nerves encountered in the lateral approach to the distal part of the fibula. J Bone Joint Surg Am. 1995; 77(7):1021-1024.

24. Gustilo RB, Anderson JT. Prevention of infection in the treatment of one thousand and twenty-five open fractures of long bones: retrospective and prospective analyses. J Bone Joint Surg Am. 1976; 58:453-458.

25. Gustilo RB, Mendoza RM, Williams DN. Problems in the management of type III (severe) open fractures: a new classification of type III open fractures. J Trauma. 1984; 24:742-746.

26. Cooper A. Treatise on Dislocations and Fractures of Joints, 1822.

27. Broos PL, Bisschop AP. Operative treatment of ankle fractures in adults: Correlation between types of fracture and final results. Injury. 1991; 22(5):403-406.

28. Danis R. Les fractures malleolaires theorie et pratique de l'osteosynthese. Mason, Paris: Theorie et Pratique de l'Osteosynthese, 1949.

29. Weber BG. Die Verletzungen des oberen Sprunggelenkes. Bern Stuttgart: Bern: Hans Huber, 1966.

30. Kennedy JG, Johnson SM, Collins AL, et al. An evaluation of the Weber classification of ankle fractures. Injury. 1998; 29(8):577-580.

31. AO. www.aosurgery.org. AO surgery

32. Lauge-Hansen N. Fractures of the ankle. II. Combined experimental-surgical and experimental-roentgenologic investigations. Arch Surg. 1950; 60(5):957-985.

33. Leontaritis N, Hinojosa L, Panchbhavi VK. Arthroscopically detected intra-articular lesions associated with acute ankle fractures. J Bone Joint Surg Am. 2009; 91(2):333-339.

34. Glass GE BS, Sanderson F, Pearse MF, et al. The microbiological basis for a revised antibiotic regimen in high-energy tibial fractures: Preventing deep infections by nosocomial organisms. J Plast Reconstr Aesthet Surg. 2011; 64:375-380.

35. Crowley DJ, Kanakaris NK, Giannoudis PV. Debridement and wound closure of open fractures: the impact of the time factor on infection rates. Injury. 2007; 38:879-889.

36. Patzakis MJ. Orthopedics-epitomes of progress: The use of antibiotics in open fractures. West J Med. 1979; 130:62.

37. French B, Tornetta $P$ 3rd. High energy tibial shaft fractures. Orthop Clin North Am. 2002; 33:211-230.

38. Bengnér U, Johnell O, Redlund-Johnell I. Epidemiology of ankle fracture 1950 and 1980. Increasing incidence in elderly women. Acta Orthop Scand. 1986; 57(1):35-37.

39. Thur CK, Edgren G, Jansson K-Å, et al. Epidemiology of 
adult ankle fractures in Sweden between 1987 and 2004. Acta Orthop. 2012; 83(3):276281.

40. Koval KJ, Lurie J, Zhou W, et al. Ankle fractures in the elderly: What you get depends on where you live and who you see. J Orthop Trauma. 2005; 19(9):635-639.

41. Kannus $\mathrm{P}$, Palvanen $\mathrm{M}, \mathrm{Niemi} \mathrm{S}$, et al. Increasing number and incidence of low-trauma ankle fractures in elderly people: Finnish statistics during 1970-2000 and projections for the future. Bone. 2002; 31(3):430-433. 